\title{
On the Mechanisms of Haemodialysis-induced Neutropenia: A Study with Five New and Re-used Membranes
}

\author{
C. Heierli ${ }^{1}$, M. Markert ${ }^{2}$, P. H. Lambert ${ }^{3}$, T. Kuwahara ${ }^{1}$ and J. P. Wauters ${ }^{1}$ \\ ${ }^{1}$ Division of Nephrology, ${ }^{2}$ Laboratory of Clinical Chemistry, University Hospital, Lausanne, Switzerland; ${ }^{3}$ WHO Immunology \\ Training Unit, Geneva, Switzerland
}

\begin{abstract}
A prospective study was undertaken in 12 haemodialysed patients successively treated on five new as well as re-used dialyser membranes, that is cuprophane, cellulose acetate, polysulphone, polycarbonate, and polyacrylonitrile. A significant reduction of neutrophils occurred with every membrane during their first use, which improved only with cuprophane upon re-use. Thrombocytopenia was noted only when neutropenia reached very low values. Monocyte reduction occurred on cuprophane, cellulose acetate and polycarbonate, but did not improve during second use. $\mathrm{C}_{3} \mathrm{~d}$ accumulation paralleled the time course of neutropenia only with cuprophane and cellulose acetate. Plasma collected at the extreme of neutropenia induced aggregation of control and predialysis cells, but did not aggregate autologous dialysed neutrophils collected at $5 \mathrm{~min}$. Our data indicate that the mechanism linking complement activation to neutropenia is probably triggered by more than one factor.
\end{abstract}

Key words: Haemodialysis; Neutropenia; Thrombocytopenia; Monocytopenia; Complement; Aggregation

\section{Introduction}

A marked neutropenia occurs immediately after the start of a haemodialysis session [1]. Although contact between blood and dialyser membrane is necessary to induce this phenomenon, almost all the circulating neutrophils disap-

Correspondence and offprint requests 10: Dr J. P. Wauters, Division of Nephrology, CHUV, 1011 Lausanne, Switzerland. pear before $20 \%$ of the blood has actually circulated through the dialyser $[1,2]$. This neutropenia is mainly due to margination of the neutrophils in the pulmonary capillaries [3] and is thought to be a consequence of dialyserassociated activation of the complement system through the alternative pathway [4-7]. One of the fragments of this complement cascade, the $\mathrm{C}_{5} \mathrm{a}$, was suggested to play the major role in this phenomenon by triggering aggregation of the circulating polymorphonuclear leucocytes (polymorph) $[8,9]$. Cells return to circulation well before the end of dialysis, despite the persisting complement activation [10]. The transience of the pulmonary leukostasis has been attributed to an acquired refractoriness of granulocytes to repeated complement stimulation most likely resulting from down-regulation of membrane receptors for $\mathrm{C}_{5}$ a desarg [11].

However, not only plasmatic but also cellular factors are able to produce aggregation of neutrophils in vitro and in vivo [12,13]. Indeed, neutrophil cationic proteins and platelet activating factor released from polymorph and platelets have been shown to induce an aggregating activity which could lead to granulocyte sequestration [14-16]. More recently it has been proposed that complement activation in vivo is associated with up-regulation of neutrophilic $\mathrm{C}_{3} b$ receptors, indicating that this cellular response is a physiological mechanism by which this cell can augment its capacity for responding to $\mathrm{C}_{3}$ b opsonised material [17]. Another recent finding has identified a phagocyte-surface glycoprotein called Mo 1, which appears to be involved in neutrophil adhesion and whose expression is increased and coincides with the maximum 
Table 1. Characteristics of the patients

\begin{tabular}{|c|c|c|c|c|c|}
\hline Initials & Age & Sex & Renal disease & $\begin{array}{l}\text { Duration } \\
\text { of } \mathrm{HD} \\
\text { (months) }\end{array}$ & $\begin{array}{l}\text { Heparin } \\
\text { start/ } \\
\text { hourly }\end{array}$ \\
\hline $\begin{array}{l}\text { AF } \\
\text { MB } \\
\text { MLD } \\
\text { SP } \\
\text { GS } \\
\text { GP } \\
\text { DM } \\
\text { MJ } \\
\text { ES } \\
\text { NS } \\
\text { CC } \\
\text { KR }\end{array}$ & $\begin{array}{l}47 \\
78 \\
60 \\
59 \\
53 \\
70 \\
49 \\
51 \\
80 \\
64 \\
65 \\
64\end{array}$ & $\begin{array}{l}f \\
f \\
f \\
f \\
m \\
m \\
m \\
f \\
m \\
m\end{array}$ & $\begin{array}{l}\text { Chronic interstitial nephritis } \\
\text { Chronic interstitial nephritis } \\
\text { Chronic glomerulonephritis } \\
\text { Nephroangiosclerosis } \\
\text { Analgesic nephropathy } \\
\text { Analgesic nephropathy } \\
\text { Renal polycystic disease } \\
\text { Renal polycystic disease } \\
\text { Analgesic nephropathy } \\
\text { Chronic interstitial nephritis } \\
\text { Nephroangiosclerosis } \\
\text { Analgesic nephropathy }\end{array}$ & $\begin{array}{r}109 \\
101 \\
88 \\
62 \\
21 \\
18 \\
15 \\
13 \\
13 \\
6 \\
2 \\
2\end{array}$ & $\begin{array}{l}2500 / 250 \\
5000 / 375 \\
4000 / 750 \\
2500 / 250 \\
2000 / 500 \\
4000 / 1000 \\
5000 / 250 \\
2000 / 250 \\
3000 / 700 \\
5000 / 500 \\
2500 / 500 \\
3000 / 500\end{array}$ \\
\hline
\end{tabular}

* Died after first month of study

reduction in neutrophil count during dialysis on a new cuprophane membrane [18]. It was suggested that this increased expression of Mo l could provide a mechanism for initiating sequestration of neutrophils and neutropenia during haemodialysis.

Neutropenia and complement activation have been shown to be attenuated on new non-cellulosic membranes [19-25] and on re-used cuprophane [26-30], but the effect of re-use has never been systematically studied on non-cellulosic membranes.

The above-described parameters have now become the most investigated aspects of the biocompatibility of dialyser membranes [31]. In order to evaluate the biocompatibility of five different membranes and the effect of their re-use, and to gain a better insight into the mechanism of haemodialysis-related neutropenia, a prospective crossover study was undertaken in 12 patients successively dialysed on cuprophane, cellulose acetate, polysulphone, polycarbonate, and polyacrylonitrile. Simultaneous determinations of white blood cell (WBC) counts, platelet counts, the $\mathrm{C}_{3} \mathrm{~d}$ complement degradation product, and the aggregating capacity of dialysed neutrophils were performed throughout the dialysis session.

\section{Methods}

\section{Patients}

Twelve patients (Table 1), seven females and five males, from 47 to 80 years old, gave informed consent to participate in this study. All patients had been dialysed for 2 to 109 months, with a mean duration of 32 months. Dialysis sessions were of $3 \times 3 \mathrm{~h} /$ week. None of these patients were diabetic, had any acute illness, nor took corticosteroids during the study period. Patient MB died after the first month of study owing to a cerebral vascular accident at the age of 78 .

\section{Haemodialysis Procedure}

Two cellulosic and three synthetic membranes were tested successively during first use (I) and $48 \mathrm{~h}$ later during second use (II). The investigations were done monthly and, in the intermediate period the patients were dialysed on cuprophane which was also reprocessed with formalin $3 \%$ (one new filter per week).

All 12 patients began the study with cuprophane hollow-fibre dialyser, which was their usual membrane (CF 1511; Travenol, USA; surface area $1.3 \mathrm{~m}^{2}$ ). At each subsequent month the following dialysers were tested: cellulose acetate hollow fibre dialyser (cellulose acetate 170; Travenol, USA; surface area $1.7 \mathrm{~m}^{2}$ ), polysulphone hollow fibre (F60; Fresenius, Germany; surface area $1.3 \mathrm{~m}^{2}$ ), polycarbonate plate membrane (Lundia Pro 5; Gambro Lundia, Sweden; surface area $\left.1.1 \mathrm{~m}^{2}\right)$, and finally polyacrylonitrile plate membrane (Biospal $2400 \mathrm{~S}$; Hospal, France, surface area $1.0 \mathrm{~m}^{2}$ ).

The blood flow rate was maintained at $250-300 \mathrm{ml} / \mathrm{min}$ from an internal arteriovenous fistula and the dialysate, which contained acetate, had a flow rate of $500 \mathrm{ml} / \mathrm{min}$ in a single-pass mode. Heparin was administered at a dose of $2000-5000 \mathrm{U}$ at the start and $250-1000 \mathrm{U}$ hourly by continuous infusion.

\section{Dialyser Re-use}

A semi-automated method was applied as follows: back filtration was carried out with tap water treated by reverse osmosis, and the complete blood removal was checked visually. The dialyser was filled with $3 \%$ formalin in both the dialysate and the blood compartments, and subsequently stored at $4^{\circ} \mathrm{C}$. According to the manufacturer's 
instructions, an initial rinsing with $1 \%$ hypochlorite was carried out exclusively for polyacrylonitrile before continuing the above described re-use method. Immediately prior to the next use, the formalin was washed out for $20 \mathrm{~min}$ from the blood compartment with $3000 \mathrm{ml}$ saline, and simultaneously from the dialysate compartment with dialysate at a flow of $500 \mathrm{ml} / \mathrm{min}$.

\section{Sample Collection for Blood Cell Counts and Complement Measurements}

During each dialysis session studied, $2 \mathrm{ml}$ whole blood was initially obtained from the patient's arteriovenous fistula (predialysis, time 0). Four additional blood samples were drawn from the venous (outflow) line of the dialyser at 5, 15, $60 \mathrm{~min}$, and at the end of the dialysis session. The blood samples were immediately placed into test tubes containing $3.3 \mathrm{mg}$ potassium-ethylenediaminetetraacetic acid (K-EDTA). During the whole study all the samples were taken by the same person in order to improve the time reliability. The WBC counts were performed using an automated haematology analyser (Sysmex CC-800), and differential counts of granulocytes as well as monocytes and platelets counts were carried out manually through the study by the same person.

\section{Complement Measurements}

The level of $\mathrm{C}_{3} \mathrm{~d}$ generated by activation of the complement system was measured in a two-step procedure [32]. Native $C_{3}$ and high-molecular-weight fragments $C_{3} b$ and $\mathrm{C}_{3} \mathrm{c}$ were precipitated with polyethylene glycol. The $\mathrm{C}_{3} \mathrm{~d}-$ containing supernatant was assayed by single radial immunodiffusion (RID) with anti- $\mathrm{C}_{3} \mathrm{~d}$ antiserum (Behring Werke $A G$ ). $C_{5}$ a desarg antigen was performed with a commercial radioimmunoassay kit (Upjohn Co, Kalamazoo, Michigan).

\section{Granulocyte Isolation}

Three millilitres of blood at times 0 and $60 \mathrm{~min}$, and $6 \mathrm{ml}$ at times 5 and $15 \mathrm{~min}$ were collected in heparinised tubes $(10 \mathrm{U} / \mathrm{ml})$ from the outflow line of the dialyser. Purified preparations of polymorphonuclear leucocytes were obtained in a single centrifugation step on discontinuous density Percoll gradients (Pharmacia, Uppsala, Sweden), according to a published technique [33] which was slightly modified. Isotonic Percoll was obtained by diluting 9 volumes of Percoll with a volume of $1.5 \mathrm{M} \mathrm{NaCl}$. Percoll $76 \%$ and $60 \%$ (vol/vol) were prepared by further diluting the isotonic Percoll in Ca- and Mg-free Hanks balanced salt solution (HBSS). The discontinuous gradient was

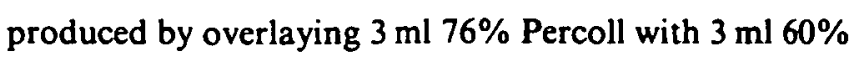
Percoll. Three millilitres heparinised undiluted blood was layered on top of the gradient and the tube was centrifuged at $350 \mathrm{G}$ for $20 \mathrm{~min}$ at $20^{\circ} \mathrm{C}$. After withdrawal of the plasma layer, which was kept on ice until use, the granulocyte layer was carefully aspirated with a Pasteur pipette and washed once in $\mathrm{Ca}^{2+}$ - and $\mathrm{Mg}^{2+}$-free $\mathrm{HBSS}$ at $350 \mathrm{G}$ for $10 \mathrm{~min}$ at $4^{\circ} \mathrm{C}$. Contaminating red cells were removed by hypotonic lysis [29]. The cells were resuspended in $\mathrm{Ca}^{2+}$ - and $\mathrm{Mg}^{2+}$-free $\mathrm{HBSS}$ containing glucose ( $5 \mathrm{mM}$ ) and human serum albumin $0.5 \%$ (HBSS/HSA) to a concentration of $2 \times 10^{7}$ polymorph/ml. The purity of the cells was assessed by cyto-centrifugation of the purified preparations and staining with May Grunwald-Giemsa. It was found that more than $93 \%$ of the cells were neutrophils. The polymorph yield calculated for dialysed polymorphs during dialysis on cuprophane, first use at time 0 , 5,15 and $60 \mathrm{~min}$ was $75.5 \% \pm 2.9$ (mean $\pm \mathrm{SEM}$ ); $70.1 \% \pm 5.9 ; 64.3 \% \pm 8.2$ and $70.1 \% \pm 6.2$ respectively. It was not significantly different from the yield of control polymorphs: $69.7 \% \pm 6.4$.

\section{Granulocyte Aggregometry}

Aggregometry was performed according to a modification of the Craddock et al method [8], with a standard platelet aggregometer $(\mathrm{H}$. Upchurch and $\mathrm{Co}$, Leicester, England). To a siliconised cuvette containing a siliconised stirring bar revolving at 1100 r.p.m., $200 \mu \mathrm{l} \mathrm{HBSS/HSA}$ containing $1.2 \mathrm{mM} \mathrm{Ca}^{2+}, 1.0 \mathrm{mM} \mathrm{Mg}^{2+}$ and $5 \mu \mathrm{g} / \mathrm{ml}$ cytochalasin B (cyto B) (Sigma), $250 \mu$ l of cell suspension was added. After a 2-min delay to allow warming of the cells, $50 \mu \mathrm{l}$ of autologous dialysed plasma or zymosanactivated plasma was added. The resulting change in light transmission was recorded. Zero per cent light transmission was calibrated with the test suspension, and $100 \%$ was calibrated with cell suspension diluted $1: 1$ with HBSS/HSA. The increment in light transmission between the initial cell preparation and the dilution was set at $18 \mathrm{~cm}$.

Zymosan (Sigma) was prepared as previously described [34]. Zymosan activated plasma was obtained by incubating $40 \mathrm{mg}$ zymosan for $30 \mathrm{~min}$ at $37^{\circ} \mathrm{C}$ in $5 \mathrm{ml}$ plasma containing $10 \mathrm{U}$ heparin per $\mathrm{ml}$. After centrifugation of the particles, zymosan-activated plasma was frozen in aliquots of $-80^{\circ} \mathrm{C}$ for not more than one month and thawed on the day of use. Cyto B was stored as a stock solution in dimethylsulphoxide (DMSO) at a concentration of $1 \mathrm{mg} / \mathrm{ml}$ at $4^{\circ} \mathrm{C}$ and diluted in HBSS/HSA for use.

\section{Statistics}

Unless otherwise stated, statistical analysis was carried out using the Wilcoxon signed-rank test for matched pairs. 


\section{Results}

\section{Effect of New and Re-used Membranes on Neutrophil Counts}

A significant reduction in the number of neutrophils occurred on every filter studied during their first use (Fig. 1). When neutropenia was greatest, only $6 \pm 1 \%$ of predialysis polymorphs remained in circulation with cuprophane, $45 \pm 11 \%$ with polycarbonate, $49 \pm 9 \%$ with cellulose acetate, $78 \pm 4 \%$ with polysulphone and $83 \pm 12 \%$ with polyacrylonitrile. Maximum neutropenia appeared as early as $5 \mathrm{~min}$ on cellulose acetate, polysulphone and polyacrylonitrile, and at $15 \mathrm{~min}$ on cuprophane and polycarbonate. A significant rebound at the end of dialysis was observed only with cuprophane.

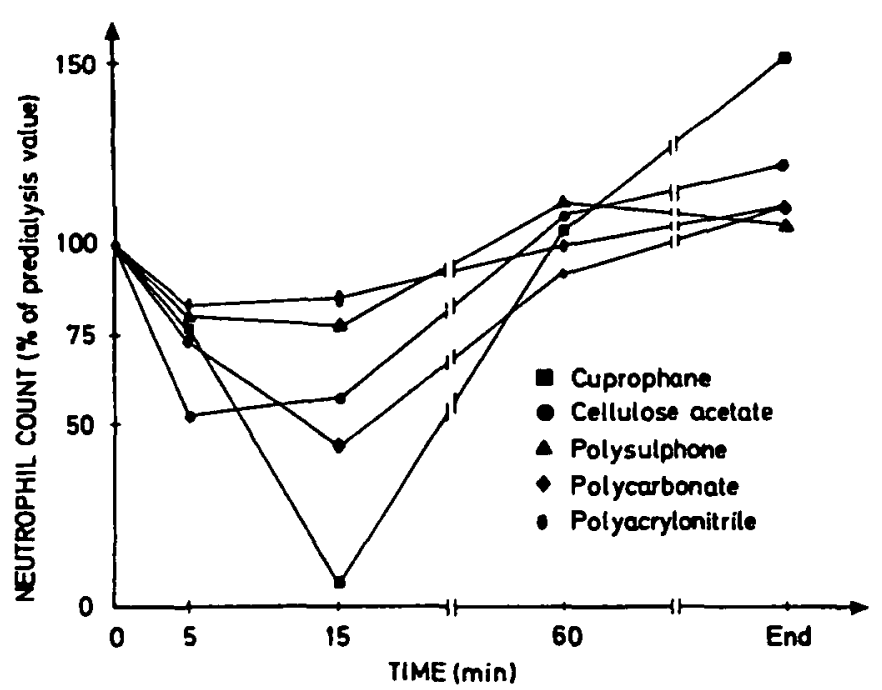

Fig. 1. Haemodialysis neutropenia during the first use of different dialyser membranes. For clarity, SEM are omitted but can be found in Table 2.

Upon re-use of the membranes (Table 2), neutropenia with cuprophane was improved from $6 \%$ to $66 \%$, but there was no improvement with re-use of cellulose acetate, polysulphone, polycarbonate or polyacrylonitrile. Maximum neutropenia appeared at the same time as during first use for all membranes except for cellulose acetate and polysulphone, which switched their maximum neutropenia from 5 to $15 \mathrm{~min}$. At the end of dialysis cuprophane, cellulose acetate and polycarbonate showed a significant rebound of the polymorph count.

During the 5 months of the study the neutrophil counts at time 0 did not show any significant variation: (cuprophane $4.2 \pm 0.5$; cellulose acetate $4.4 \pm 0.7$; polysulphone $4.1 \pm 0.3$; polycarbonate $4.6 \pm 0.5$; polyacrylonitrile $4.1 \pm 0.6) \times 10^{9} / 1$.

\section{Monocyte Count}

Although the time course of monocyte reduction was comparable to that of neutrophils, important differences were observed, depending on the membrane (Table 3). Monocytopenia was substantial with cuprophane, but improved upon re-use. With cellulose acetate and polycarbonate, monocytopenia remained the same upon re-use and was of a similar extent to the neutropenia. Polysulphone showed no significant reduction of monocytes on first use, but only on second use (47\%). Finally, polyacrylonitrile produced a substantial monocytopenia during first use $(62 \%)$ whereas only a slight neutrophil fall was evidenced. This monocytopenia completely disappeared upon re-use of the membrane.

\section{Platelet Count}

During first use a significant reduction in thrombocytes occurred only with cuprophane (Table 4). However, during re-use a significant thrombocytopenia occurred with cellulose acetate and polycarbonate. It started at $5 \mathrm{~min}$ and continued to decrease until the 15 th min. All the values had returned to baseline at $60 \mathrm{~min}$ and remained stable till the end of the dialysis.

\section{Complement Activation}

The kinetics of the generation of $\mathrm{C}_{3} \mathrm{~d}$ showed a significant increase by $5 \mathrm{~min}$ for all the membranes tested during first and second use except for polyacrylonitrile (Fig. 2a-e). Interestingly, $\mathrm{C}_{3} \mathrm{~d}$ paralleled the time course of neutropenia during the early phase of haemodialysis on cuprophane and cellulose acetate only. On the other membranes, $\mathrm{C}_{3} \mathrm{~d}$ accumulated in a striking manner at $60 \mathrm{~min}$ and also at the end of dialysis. Finally re-use produced no improvement of $\mathrm{C}_{3} \mathrm{~d}$ values at maximum neutropenia except on cuprophane. In the plasma of two patients chosen at random, signs of complement activation were investigated by measuring changes in plasma $\mathrm{C}_{5}$ a desarg during dialysis with first use cuprophane, first use cellulose acetate, and polycarbonate first and second use. An indicative and positive correlation was found between $C_{5} a$ and $C_{3} d$ $(R 0.57 ; 0.79 ; 0.45$ and 0.53 respectively), suggesting that accumulation of $\mathrm{C}_{3} \mathrm{~d}$ follows the same kinetics as $\mathrm{C}_{5}$ a desarg during haemodialysis.

\section{Relationship Between Granulocytopenia and Comp- lement Activation}

By comparing the accumulation of $\mathrm{C}_{3} \mathrm{~d}$ when neutropenia was most marked, striking differences were observed 

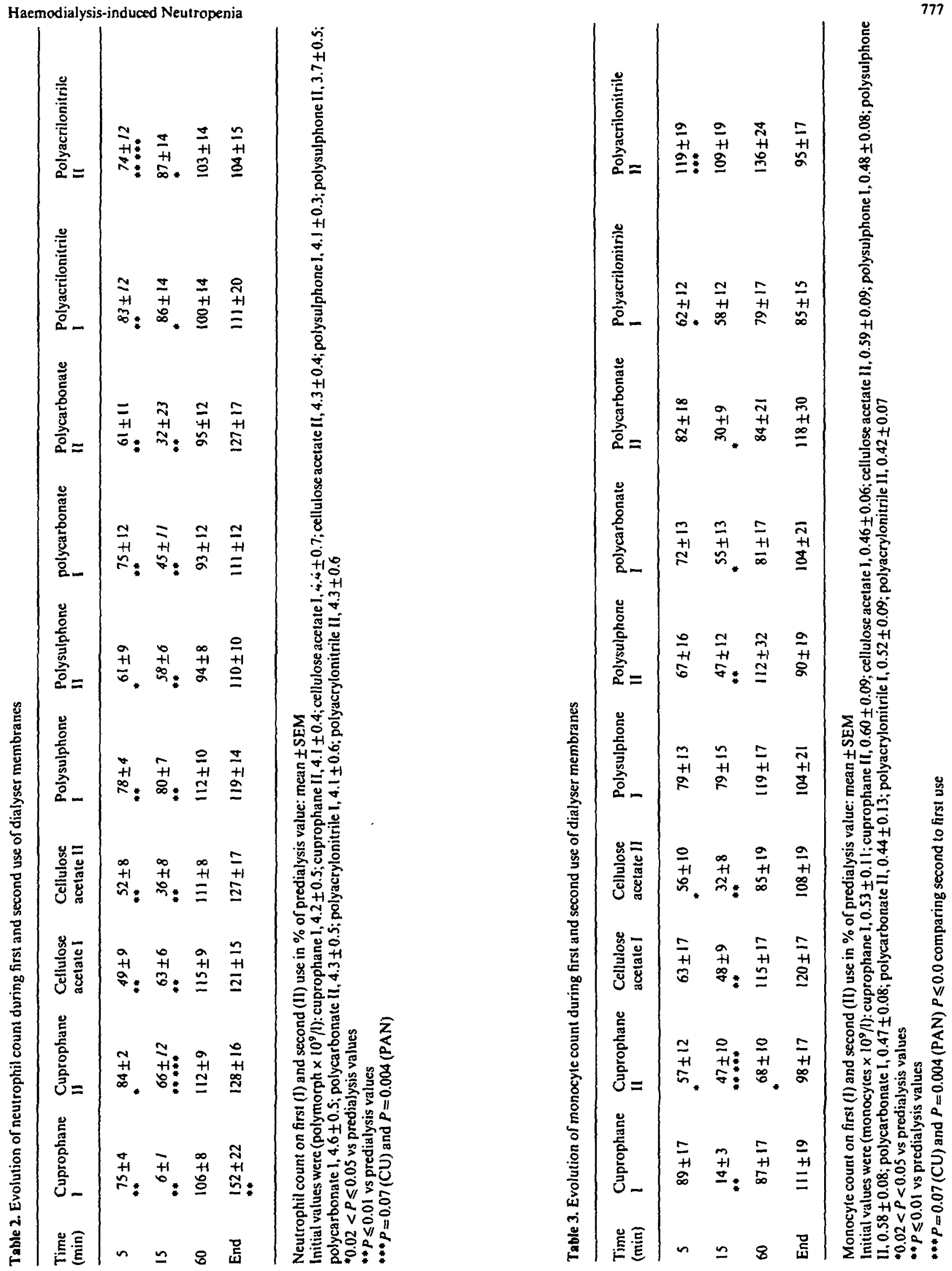


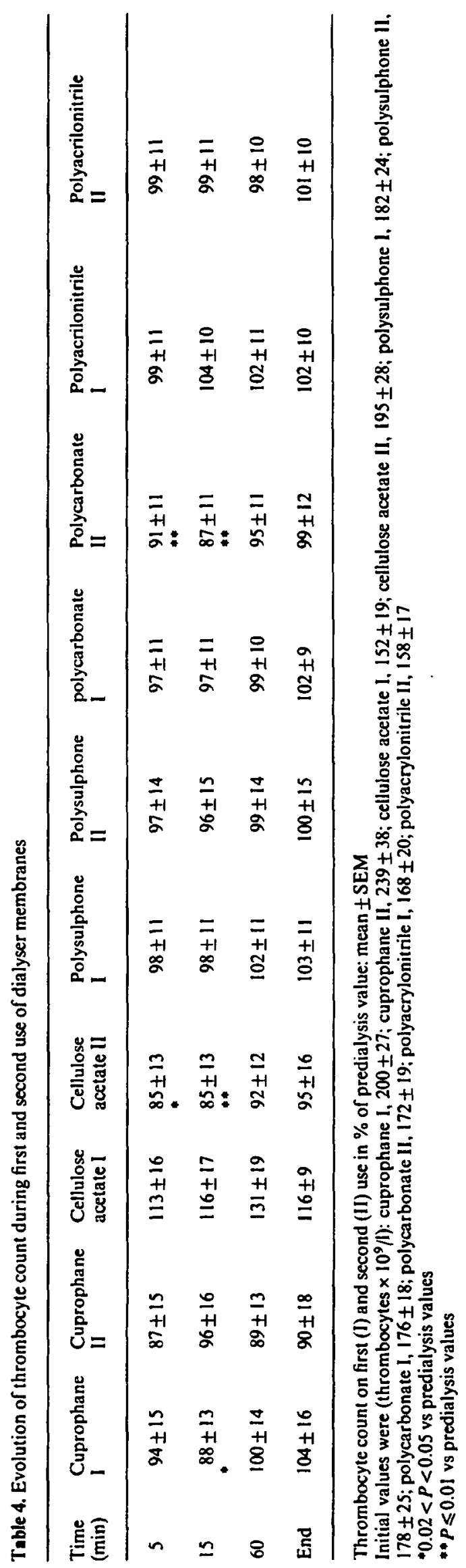



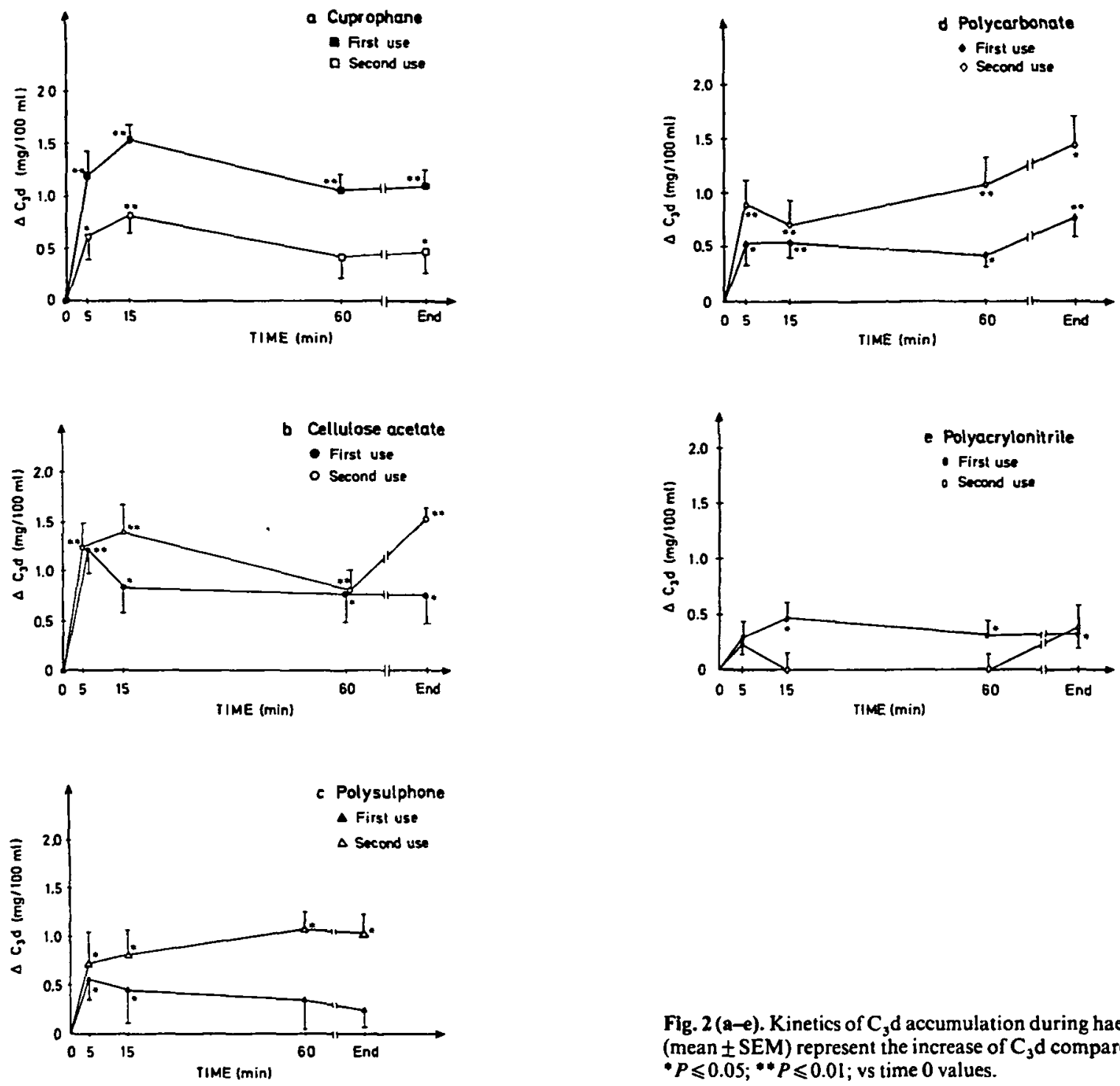

Fig. 2 (a-e). Kinetics of $\mathrm{C}_{3} \mathrm{~d}$ accumulation during haemodialysis. Values (mean $\pm S E M$ ) represent the increase of $C_{3} d$ compared to time 0 values. - $P \leqslant 0.05 ; * P \leqslant 0.01$; vs time 0 values.

between membranes (Fig. 3). A similar increase of $\mathrm{C}_{3} \mathrm{~d}$ appeared with cuprophane and cellulose acetate during first use, whereas the extent of the neutrophil reduction with cuprophane $(94 \%)$ was almost twice as large as that observed on cellulose acetate $(51 \%)(P<0.001$ evaluated using paired $t$-test as for all the subsequent comparisons of this paragraph). Polycarbonate and polysulphone activated complement to the same extent, whereas the neutrophil reduction with polycarbonate was more than twice as large as that with polysulphone $(P<0.002)$. These comparisons between polycarbonate and polysulphone were again observed on second use $(P<0.002)$. Furthermore, the neutrophil reductions during second use were the same with cellulose acetate as with polycarbonate, and were the same with polysulphone as with polyacrylonitrile, but the $\mathrm{C}_{3} \mathrm{~d}$ accumulation in cellulose acetate was twice that of polycarbonate $(P<0.02)$ and three times larger with polysulphone than with polyacrylonitrile
$(P<0.02)$. Finally, when comparing first and second use it appears that complement activation at the time of maximum neutropenia was reduced only with cuprophane.

\section{Time Course of Dialysed Polymorph Aggregation}

Neutrophils isolated at different times during haemodialysis with cuprophane, cellulose acetate, polysulphone, and polyacrylonitrile were assessed for their ability to aggregate in response to their plasma collected at the extreme of neutropenia ( $15 \mathrm{~min}$ for cuprophane, cellulose acetate, and polysulphone and $5 \mathrm{~min}$ for polyacrylonitrile) (Fig. 4). Time 0 dialysed polymorphs and control polymorphs responded equally well to the respective plasmas collected at the maximum neutropenia for each membrane, indicating that there is no defect in polymorphs from dialysed patients at the start of dialysis. However, 


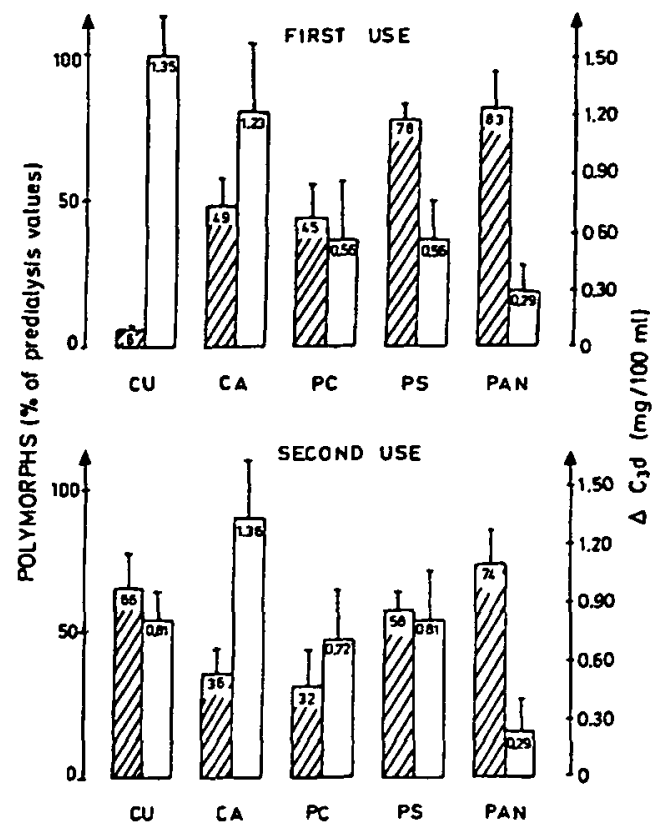

Fig. 3. Maximum neutropenia and related complement activation. Values are mean $\pm S E M$.

there was no correlation between the degree of aggregation observed and the amount of $\mathrm{C}_{3} \mathrm{~d}$ accumulated within the plasma used for stimulation.
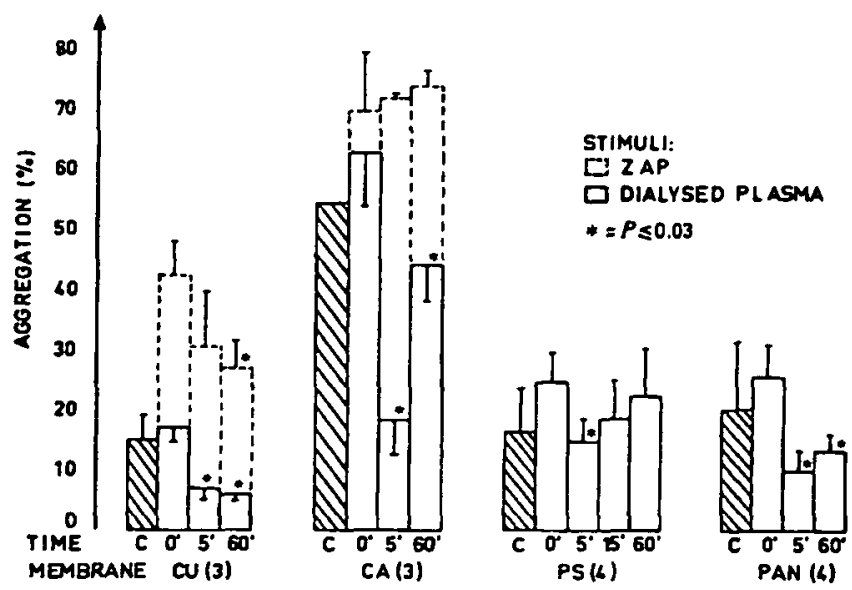

Fig. 4. Aggregation responses of dialysed polymorphs collected at differ ent times of dialysis. Control polymorphs (C) $\mathbb{N}$, and dialysed poly. morphs $\square$, from the different membranes were stimulated with their autologous plasma collected at the maximum of neutropenia, i.e. $15 \mathrm{~min}$ for cuprophane, cellulose acetate and polysulphone and $5 \mathrm{~min}$ for polyacrylonitrile. Symbol $: . ;$ represents the stimulation with zymosan activated plasma of cuprophane- and cellulose acetate-dialysed polymorphs. In brackets the number of patients investigated on each membrane. Bars denote the SEM and $P \leqslant 0.03$ vs time 0 dialysed polymorphs. Statistical significance was evaluated with the paired t-test.

Cells collected after $5 \mathrm{~min}$ of dialysis showed a striking reduction in their aggregating capacity (Figs 4,5 ). The aggregation responses at $5 \mathrm{~min}$ compared to time 0 were $46 \%, 29 \%, 59 \%$ and $39 \%$ for cuprophane, cellulose acetate, polysulphone and polyacrylonitrile respectively.
Owing to the small amount of polymorphs collected at the maximum neutropenia, it was only possible to measure this aggregating activity with the polysulphone 15-min dialysed polymorphs. The aggregating response had already returned to time 0 values. Aggregating capacity at $60 \mathrm{~min}$ remained impaired on cuprophane and polyacrylonitrile dialysed cells, but on polysulphone a return to normal values and on cellulose acetate a trend towards normal values was observed.

To determine whether the alterations in neutrophil aggregometry responses were related to $\mathrm{C}_{5} \mathrm{a}$, zymosanactivated plasma containing a high amount of activated complement $\left(7.72 \pm 1.25 \mathrm{mg} \mathrm{C}_{3} \mathrm{~d}\right.$. $\left.100 \mathrm{ml}^{-1}, n=4\right)$ was used as the aggregating stimulus on cells collected during cuprophane and cellulose acetate dialysis. With cuprophane, cells collected at $5 \mathrm{~min}$ retained their time 0 aggregating responses, but cells isolated at $60 \mathrm{~min}$ showed an impaired response to zymosan-activated plasma $(P<0.02)$. With cellulose acetate, cells isolated at 5 and 60 min showed a similar aggregation to time 0 cells in response to zymosan-activated plasma.

\section{Discussion}

The present study of five membranes and their re-use enables a comparative evaluation of membrane biocom. patibility, based on white blood cells, platelet counts and complement activation as parameters. The comparison is valid since all five membranes were studied successively with the same patients. A rough classification can then be proposed: on first use cuprophane, as expected, appears the least biocompatible; in contrast polysulphone and polyacrylonitrile seem to possess the highest biocompatibility properties, whilecellulose acetate and polycarbonate are in an intermediate place.

Re-use has been claimed to be associated with improved neutropenia and complement activation $[23,26-30]$. These studies, however, concerned exclusively cuprophane membranes usually processed with formalin. This observation was confirmed in our study. On the contrary, cellulose acetate, as shown by others [30], and polysulphone or polycarbonate did not show any improvement of neutropenia, monocytopenia and complement activation upon their second use. Polyacrylonitrile showed an even more marked decrease of the slight neutrophil reduction from $83 \%$ to $74 \%$ on second use (after hypochlorite rinsing), but monocyte counts remained unchanged and no significant complement activation was evidenced. The beneficial effect of re-use on cuprophane has been attributed to a protective protein coating of the dialyser surface during its first use. This 'protein cake' is thought not to be removed by the usual re-use technique enabling the membrane to become more biocompatible on second use. 


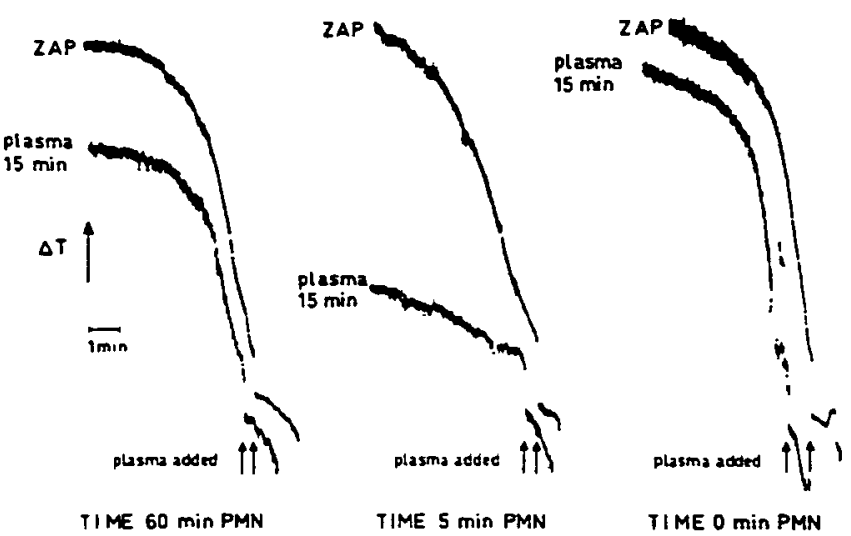

Fig. 5. Aggregating activity of cellulose acetate dialysed polymorphs induced by autologous 15 -min plasma and zymosan-activated plasma.

Furthermore, a fixation of $\mathrm{C}_{3}$ b on the surface of cuprophane during first use, blocking complement-activating sites has been demonstrated [27]. Re-use of this ' $\mathrm{C}_{3} \mathrm{~b}$ coated' dialyser was then associated with only modest complement activation and haemodialysis neutropenia. In our study the absence of improvement of neutropenia and complement activation implies that these protective mechanisms described for cuprophane do not apply to modified cellulose and synthetic membranes. The reduction of polymorphs upon re-use with polyacrylonitrile could be attributed to the reprocessing technique, since hypochlorite has been shown to remove the protective protein coating [29], especially $\mathrm{C}_{3} \mathrm{~b}[21]$.

Either the plasma proteins and/or $\mathrm{C}_{3} \mathrm{~b}$ were unble to be fixed on the membrane or the re-use technique was more stringent for cellulose acetate, polysulphone, polycarbonate, and polyacrylonitrile than it was for cuprophane. Whether the re-use technique removes the protein coating or even damages the membrane, or whether different membrane hydraulic properties play a role, will necessitate further investigation. Thus, when re-used, the five membranes tested modified their biocompatibility, bringing cuprophane to the level of polysulphone and polyacrylonitrile, whereas cellulose acetate and polycarbonate remained intermediate.

Complement activation has been closely linked to neutropenia soon after the initiation of a haemodialysis session [7]. More recently, measurement of complement fragment $\mathrm{C}_{3} \mathrm{~d}$ has been shown to be an appropriate cumulative marker of complement activation during haemodialysis [35]. However $\mathrm{C}_{3} \mathrm{~d}$ might underestimate activation events, since $C_{3}$ bi, which contains the $C_{3} d$ epitope, has been shown to be membrane bound on cuprophane [25]. It serves only as a distant marker of complement activaion when compared to $\mathrm{C}_{3}$ a or $\mathrm{C}_{5} \mathrm{a}$, but its longer half-life makes it a more stable index.

In addition, the positive correlation observed between $\mathrm{C}_{3} \mathrm{~d}$ accumulation and $\mathrm{C}_{5}$ a desarg suggests that these two indicators of complement activation follow the same kinetics, as also demonstrated by others [36,37], thus reflecting the same in vivo phenomenon. Our results show that complement was related to the neutropenia, but that it participated in a quantitatively different way with each membrane. Indeed, for a relatively low complement activation there was a severe neutrophil reduction with one membrane (polycarbonate II), whereas the same neutrophil change corresponded to a much greater complement activation with another membrane (cellulose acetate II). Despite identical complement activation for cuprophane I and cellulose acetate I, there was a large difference in neutropenia.

These discrepancies suggest that complement is probably not the only factor leading to neutropenia. Thrombocytopenia only appeared when neutropenia reached very low values as seen during first use of cuprophane and second use of cellulose acetate and polycarbonate. In contrast to a recent study [38], this cellular event did not correlate with the degree of complement activation as measured by the $\mathrm{C}_{3} \mathrm{~d}$ RID method. Indeed, thrombocytopenia could not be detected during the first use of cellulose acetate and polycarbonate despite the fact that complement was activated to the same extent as during their second use when the greatest thrombocytopenia was noted. Monocytes were affected in a somehow different way, and again their reduction did not correlate with the degree of complement activation.

These observations support the idea that the different functional modifications of the cells depend both on the cell type and the dialysis membrane.

To better understand the intimate mechanisms leading to neutropenia, the functional activity of dialysed polymorphs were investigated. The aggregation of granulocytes seems to be the final step leading to pulmonary sequestration [3]. The present study on aggregation was undertaken not only to demonstrate complement activation in dialysed plasma as previously proposed [39], but also to evaluate the aggregating capacity of isolated dialysed polymorphs especially during the very early phase of dialysis. Plasma collected at the extreme of neutropenia induced aggregation of control cells and of predialysis polymorphs, but to our surprise this same activated plasma did not aggregate autologous polymorphs collected at $5 \mathrm{~min}$. This phenomenon was observed with all the membranes studied, even in the absence of severe neutropenia. In contrast, these polymorphs retained their aggregating responses to the higher concentration of complement present in zymosan-activated plasma which might well overcome the refractoriness of these cells. These results could be consistent with the notion of downregulation of cellular responses to complement as described for dialysed cells collected $2 \mathrm{~h}$ after the onset of dialysis $[11,40]$. However, there was no correlation between the degree of $\mathrm{C}_{3} \mathrm{~d}$ accumulation and the aggregation activity of the dialysed plasma tested on control and 
predialysis polymorphs. After $60 \mathrm{~min}$ of dialysis polymorphs were still unresponsive to plasma collected when neutropenia was extreme. This was true not only with cuprophane - a membrane with a high stimulatory power of complement-but also with polyacrylonitrile, with the lowest capacity of activating complement. In fact polymorphs remained unresponsive only on membranes where the circulating complement was still significantly activated at $60 \mathrm{~min}$. Some of these discrepancies could be explained by the behaviour of the dialysis membrane toward complement. It has been shown that $\mathrm{C}_{3}$ a desarg and $C_{5}$ a des arg are adsorbed on polyacrylonitrile [6].

It has also been demonstrated that circulating polymorphs contain a subpopulation of approximately $20 \%$ which show abnormal adherence, chemotaxis, phagocytosis, and defective ability to form Fc rosettes [41]. This functionally defective population has been reported to predominate in the circulation after 15-20 min of haemodialysis with cuprophane or injection of $\mathrm{C}_{5}$ a desarg [42]. Furthermore, neutrophils harvested at the maximum neutropenia during cuprophane and polycarbonate dialysis were unable to respond equally well to opsonised zymosan or other soluble stimuli $[43,44]$. The mechanisms by which these cells become functionally defective is at present unknown. It is possible that activated complement has decreased the ability of these cells to respond to a subsequent stimulation through a process of stimulusspecific desensitisation [45]. Indeed, polymorphs exposed to $\mathrm{C}_{5}$ a were deactivated concomitantly to an increased number of f-Met-Leu-Phe receptors [46]. An increased number of polymorph $\mathrm{C}_{3} \mathrm{~b}$ receptors were also observed during haemodialysis on cellulosic membrane [17], which could explain the metabolic defect in response to opsonised zymosan. This might partly explain the different behaviour of dialysed polymorphs in response to aggregating stimuli.

However, the discrepancies between the degree of complement activation and leukopenia on one hand and the aggregating behaviour of 5-min dialysed polymorphs on the other indicate that other mechanisms could play a role. Since the cells leaving the filter before the maximum neutropenia do not respond, they will probably not be the cells aggregating in the lung capillaries. These observations suggest that a direct cell-membrane interaction should be considered as an additional or alternative mechanism.

Acknowledgements. The authors wish to thank Martine Vaglio (Laboratory of Clinical Chemistry) and Anita Schubert (Division of Haematology) for their worthy technical assistance, Dr A. Marazzi and A. Santos for their help in the statistical analysis. The authors also thank the patients and staff of the Dialysis Unit at the Lausanne University Hospital.

\section{References}

1. Kaplow LS, Goffinet JA. Profound neutropenia during the early phase of hemodialysis. JAMA 1968; 203: 133-135
2. Gral T, Scroth P, De Palma JR, Gordon A. Leukocyte dynamics with three types of hemodialyzers. Trans Am Soc Artif Intern Organs 1969; 15: 45-49

3. Thoren M, Goffinet JA, Kaplow LS. Pulmonary bed sequestration of neutrophils during hemodialysis. Blood 1970; 36: 337-340

4. Craddock PR, Fehr J, Dalmasso AP, Brigham KL, Jacob HS. Hemodialysis leucopenia: pulmonary vascular leukostasis resulting from complement activation by dialyzer cellophan membranes. $J$ Clin Invest 1977; 59: 879-888

5. Craddock PR, Hammerschmidt DE, Moldow CF, Yamada O, Jacob HS. Granulocyte aggregation as a manifestation of membrane interaction with complement: possible role in leukocyte margination, microvascular occlusion and endothelial damage. Semin Hematol 1979; 16: 140-147

6. Cheung AK, Henderson LW. Effects of complement activation by hemodialysis membranes. Am J Nephrol 1986; 6: 81-91

7. Chenoweth DE. Complement activation during hemodialysis: clinical observations, proposed mechanisms and theoretical implications. Artif Organs 1984; 8: 281-287

8. Craddock PR, Hammerschmidt D, White JG, Dalmasso AP, Jacob HS. Complement (C5a)-induced granulocyte aggregation in vitro. $J$ Clin Invest 1977; 60: 260-264

9. Craddock PR, Fehr J, Brigham KL, Kronenberg RS, Jacob HS. Complement and leukocyte-mediated pulmonary dysfunction in hemodialysis. N Engl J Med 1977; 296: 769-774

10. Brubaker LH, Nolph KD. Mechanisms of recovery from neutropenia induced by hemodialysis. Blood 1971; 38: 623-631

11. Scubitz KM, Craddock PR. Reversal of hemodialysis granulocytopenia and pulmonary leukostasis: a clinical manifestation of selective down-regulation of granulocyte responses to C5a desarg. J Clin Invest 1981; 67: 1383-1391

12. Camussi G, Segoloni G, Rotunno M, Vercellone A. Mechanism involved in acute granulocytopenia in hemodialysis. Cellmembrane direct interactions. Int J Artif Organs 1978; 1 : 123-127

13. Camussi G, Tetta $C$, Bussolino $F$ et al. Mediators of immunecomplex-induced aggregation of polymorphonuclear neutrophils. I. $\mathrm{C5a}$ anaphylatoxin, neutrophil cationic proteins and their cleavage fragments. Int Arch Allergy Appl Immunol 1980; 62: 1-15

14. Camussi G, Pacitti A, Tetta C et al. Mechanisms of neutropenia in hemodialysis. Trans Am Soc Artif Intern Organs 1984; 30: 364-368

15. Tetta C, Jeantet A, Camussi $G$ et al. Direct interaction between polymorphonuclear neutrophils and cuprophan membranes in a plasma-free model of dialysis. Proc Eur Dial Transplant Assoc 1984; 21: $150-155$

16. Luciak M, Tchórzewski H, Trznadel K. Release of neutrophil granule factors during early period of hemodialysis: a possible cause of hemodialysis neutropenia. Nephron 1984; 37: 30-34

17. Lee J, Hakim RM, Fearon DT. Increased expression of the $C_{3} b$ receptor by neutrophils and complement activation during hemodialysis. Clin Immunol 1984; 56: 205-214

18. Amaout MA, Hakim RM, Todd IIl RF, Dana N, Colten HR. Increased expression of an adhesion-promoting surface glycoprotein in the granulocytopenia of hemodialysis. $N$ Engl $J$ Med $1985 ; 312: 457-462$

19. Aljama P, Bird PAE, Ward MK et al. Hemodialysis-induced leucopenia and activation of complement: effects of different membranes. Proc Eur Dial Transplant Assoc 1978; 15: 144-151

20. Jacob AI, Gavellas G, Zarco R, Perez G, Bourgoignie JJ. Leukopenia, hypoxia and complement function with different hemodialysis membranes. Kidney Int 1980; 18: 505-509

21. Ivanovich $P$, Chenoweth $D E$, Schmidt $R$ et al. Symptoms and activation of granulocytes and complement with two dialysis membranes. Kidney Int 1983; 24: 758-763

22. Hakim RM, Lowrie EG. Hemodialysis-associated neutropenia and hypoxemia: the effect of dialyzer membrane materials. Nephron 1982; 32: 32-39

23. Hoenich NA, Woffindin C, Qureshi M, Kerr DNS. Membraneinduced leucopenia. Contrib Nephrol 1983; 36: 1-8

24. Amadori A, Candi P, Sasdelli M et al. Hemodialysis leukopenia and complement function with different dialyzers. Kidney Int 1983; 24: $775-781$ 
25. Chenoweth DE, Cheung AK, Henderson LW. Anaphylatoxin formation during hemodialysis: effect of different dialyzer membranes. Kidney Int 1983; 24: 764-769

26. Savdie E, Bruce L, Vincent PC. Modified neutropenic response to re-used dialyzers in patients with chronic renal failure. Clin Nephrol 1977; 8: 422-428

27. Chenoweth DE, Cheung AK, Ward DM, Henderson LW. Anaphylatoxin formation during hemodialysis: comparison of new and re-used dialyzers. Kidney Int 1983; 24: 770-774

28. Stoncek DF, Keshaviah P, Craddock PR, Hammerschmidt DE. Effect of dialyzer re-use on complement activation and neutropenia in hemodialysis. J Lab Clin Med 1984; 104: 304-31 I

29. Hoenich NA, Johnston SRD, Woffindin C, Kerr DNS. Hemodialysis leucopenia: the role of membrane type and re-use. Contrib Nephrol 1984; 37: 120-128

30. Hakim RM, Fearon DT, Lazarus M. Biocompatibility of dialysis membranes: effect of chronic complement activation. Kidney Int 1984; 26: 194-200

31. Klinkmann $\mathrm{H}$, Wolf $\mathrm{H}$, Schmitt $\mathrm{E}$. Definition of biocompatibility. Contrib Nephrol 1984; 37: 70-77

32. Perrin LH, Lambert PH, Miescher PA. Complement breakdown products in plasma from patients with systemic lupus erythematosus and patients with membranoproliferative or other glomerulonephritis. J Clin Invest 1975; 56: 165-176

33. Hjorth R, Jonsson AK, Vretblad P. A rapid method for purification of human granulocytes using Percoll $(\mathbf{R})$ : a comparison with dextran sedimentation. J Immunol Methods 1981; 43: 95-101

34. Markert M, Andrews PC, Babior BM. Measurement of $\mathrm{O}_{2}$ production by human neutrophils: the preparation and assay of NADPH oxidase-containing partictes from human neutrophils. Methods Enzymol 1984; 105: 358-365

35. Knudsen F, Nielsen AH, Pedersem JO, Jersild C. Generation of complement $C_{3}$ d within artificial kidneys. Blood Purif 1984; 2: $181-186$

36. Knudsen F, Nielsen AH, Peciersen JO, Jersild C. Activation of complement, generation of C5a, leukopenia and hypoxemia: interlinked membrane-dependent events during hemodialysis. Blood Purif 1984; 2: 98-107

37. Wegmuller E, Montandon A, Nydegger U, Descoeudres $C$. Biocompatibility of different hemodialysis membranes: activation of complement and leukopenia. Intern J Artif Organs 1986; 9: 85-92

38. Hakim RM, Schafer AI. Hemodialysis-associated platelet activation and thrombocytopenia. Am J Med 1985; 78: 575-580

39. Hammerschmidt DE, Bowers TK, Lammi-Keefe CJ, Jacob HS, Craddock PR. Granulocyte aggregometry: a sensitive technique for the detection of C5a and complement activation. Blood 1980; 55 : 898-902

40. O'Flaherty JT, Kreutzer DL, Showell HJ, Vitauskas G, Becker EL, Ward PA. Selective neutrophil desensitization to chemotactic factors. J Cell Biol 1979; 80: 564-572

41. Klempner MS, Gallin JI. Separation and functional characterization of human neutrophil subpopulations. Blood 1978; 51 : 659-669

42. Klempner MS, Gallin JI, Balow JE, Van Kammen DP. The effect of hemodialysis and $\mathrm{C}_{5}$ a desarg on neutrophil subpopulations. Blood 1980; 55: 777-783

43. Cohen MS, Elliot DM, Chaplinski T, Pike MM, Niedel JE. A defect in the oxidative metabolism of human polymorphonuclear leukocytes that remain in circulation early in hemodialysis. Blood 1982; 60: 1283-1289

44. Heierli C, Markert M, Frei J, Lambert PH, Wauters JP. The polycarbonate hemodialysis membrane: neutrophil, platelet, complement and chemiluminescence kinetics during first and second use. Blood Purif 1986; 4: 82-87

45. Henson PM, Zanolari B, Schwartzman NA, Hong SR. Intracellular control of human neutrophil secretion. I. $\mathrm{C}_{\mathbf{g}}$ a-induced stimulusspecific desensitization and the effects of cytochalasin B. J Immunol 1978; 121: 851-855

46. Donnabedian H, Gallin JI. Deactivation of human neutrophil chemotaxis by chemoattractants: effect on receptors for the chemotactic factor f-Met-Leu-Phe. J Immunol 1981; 127: 839-844 